\title{
How Electroconvulsive Therapy Works?: Understanding the Neurobiological Mechanisms
}

\author{
Amit Singh, Sujita Kumar Kar \\ Department of Psychiatry, King George's Medical University, Lucknow, U.P, India
}

Electroconvulsive therapy (ECT) is a time tested treatment modality for the management of various psychiatric disorders. There have been a lot of modifications in the techniques of delivering ECT over decades. Despite lots of criticisms encountered, ECT has still been used commonly in clinical practice due to its safety and efficacy. Research evidences found multiple neuro-biological mechanisms for the therapeutic effect of ECT. ECT brings about various neuro-physiological as well as neuro-chemical changes in the macro- and micro-environment of the brain. Diverse changes involving expression of genes, functional connectivity, neurochemicals, permeability of blood-brain-barrier, alteration in immune system has been suggested to be responsible for the therapeutic effects of ECT. This article reviews different neurobiological mechanisms responsible for the therapeutic efficacy of ECT.

KEY WORDS: Electroconvulsive therapy; Neurobiology; Psychiatric diagnosis.

\section{INTRODUCTION}

Electroconvulsive therapy (ECT) is a valuable therapeutic modality in psychiatric clinical practice. ${ }^{1)}$ Development of various pharmacological agents with patient friendly profile restricted the use of ECT in current clinical practice. However, it is still commonly used in the management of depression, acute manic episode, catatonia, and treatment resistant schizophrenia. ${ }^{2)}$ ECT has mood stabilizing property superior than pharmacotherapy in the management of depressive episode, manic episode as well as mixed episode in bipolar affective disorder. ${ }^{3)}$ The therapeutic response achieved through administration of ECT is usually quicker than existing psychotropic medications. The initial use of seizure for a therapeutic purpose (management of psychiatric disorder) was based on an observation which was indicative of an important biological underpinning behind the therapeutic efficacy of ECT. In early part of last century, the glial cell density in the brain of patients suffering from schizophrenia was compared with those with epilepsy. The number of glial

\footnotetext{
Received: September 26, 2016 / Revised: December 6, 2016

Accepted: December 21, 2016

Address for correspondence: Sujita Kumar Kar, MD

Department of Psychiatry, King George's Medical University, Shah

Mina Road, Chowk, Lucknow, Uttar Pradesh 226003, India

Tel: +91-9956273747, Fax: +91-522-2265416

E-mail: drsujita@gmail.com
}

cells in the brain of patients with epilepsy was higher than those suffering from schizophrenia, indicating the role of seizure in maintaining the density of glial cells. This biological observation has given birth to the idea that induction of seizure may help in restoring the glial cell number causing improvement in the psychiatric illness. ${ }^{4)}$ ECT was finally developed through series of experiments for seizure induction (initially by injecting epileptogenic chemicals, subsequently using electric stimuli for seizure induction) over past two centuries. Extensive web search in the Medline database using the keywords "Electroconvulsive therapy", "ECT", and "Neurobiology" was done. All relevant studies published till the end of July 2016 in English language were analyzed with focus on mechanism of action of ECT.

Seizures induced in human brain were demonstrated to be effective in treating psychiatric disorders as early as initial half of the last century. Yet, how this seizure activity in brain operates to ameliorate neuropsychiatric symptoms is still not completely understood. Since the very inception of electroconvulsive shock (ECS) use in clinical practice, various theories have been proposed to unravel this enigma. Growing knowledge base has helped in safer application of ECT with lesser adverse events, and a better understanding of the underlying mechanism might help in further improvisation of this therapy. Moreover, the importance of knowing the mechanism also lies in the fact

(c) This is an Open-Access article distributed under the terms of the Creative Commons Attribution Non-Commercial License (http://creativecommons.org/licenses/by-nc/4.0) which permits unrestricted non-commercial use, distribution, and reproduction in any medium, provided the original work is properly cited. 
that there have been voices raised time and again labeling ECT as inhumane treatment modality, questioning its mechanism of action. Studies have been performed on experimental animals, human subjects as well as cadaveric brain in attempts to elucidate the possible mechanisms.

\section{MAIN SUBJECTS}

\section{Mechanism of Action of ECT}

Numerous psychological, psychoanalytical and biological theories have been put forward as an endeavor to explain the therapeutic effect of ECT. Biological theories proposed, can broadly be classified into neurophysiological, neuro-biochemical, and neuroplasticity theories depending upon the effect of ECS on various aspects (functional, compositional and structural) of brain as well as underlying neuronal and glial tissues. This review aimed at understanding the developments in biological models explaining mechanisms of action of ECT.

\section{Neurophysiological Hypotheses}

The electrical impulse from ECT electrodes traverses through intermediary tissue to stimulate neurons in brain by altering their internal electrical milieu and concentration of ions. ${ }^{5)}$ Group of depolarized neurons fire simultaneously to produce a convulsion, that has been suggested to exert a therapeutic effect in various neuropsychiatric disorders. The factors determining areas of brain that get activated, includes the particulars of seizure (induced), site of electrode placement as well as patient related variables. ${ }^{6,7)}$ Generalized seizure encompasses critical brain structures such as cortex, sub-cortex, thalamus, basal ganglia and limbic system. However, certain brain areas are more strikingly involved than others. ${ }^{8)}$ Notwithstanding these differences, Postictal Suppression Index (PSI) and Burst Suppression (BS) index have been identified as robust measures that can predict adequacy of seizures in ECT. Kranaster et al. ${ }^{9)}$ had reported BS index as a marker comparable with PSI. ${ }^{9)}$ After multiple sessions of ECT the BS index reduces, which reflects the anticonvulsant effect of ECT. ${ }^{9)}$

Changes in cerebral blood flow and regional metabolism A variety of studies have shown ECT to alter the cerebral blood flow and glucose metabolism, using neuroimaging techniques such as positron emission tomography (PET), single photon emission computed tomography (SPECT) and functional magnetic resonance imaging (fMRI). Regional cerebral blood flow ( $\mathrm{rCBF}$ ) tends to increase immediately in the areas of brain with seizure activity and follows the seizure generalization pattern. ${ }^{6)}$ In addition, the changes in $\mathrm{CCBF}$ vary depending on the type of seizure, with generalized seizures causing higher variations in rCBF than missed ones. ${ }^{6,8)}$ There is a subsequent decline in rCBF shortly after ECT-induced seizures. ${ }^{10)}$

Alterations in global as well as $\mathrm{rCBF}$ have been demonstrated in mood disorders, psychosis as well as in population at higher risk of developing psychosis. ${ }^{11,12)}$ Regarding absolute levels of blood flow research findings are inconsistent. This variability might be attributable to the differences in parameters been measured, patient characteristics, illness features, treatment received and the imaging modalities used. ${ }^{13)}$ Mounting evidences in patients with depression (unipolar as well as bipolar depression) indicate significant hypometabolism in frontal gyrus. ${ }^{14,15)}$ Furthermore, Hosokawa et al. ${ }^{14)}$ showed difference in glucose metabolism pattern in patients with bipolar and unipolar depression in the form of hypometabolism in right anterior cingulate cortex (ACC) in the former, and the later exhibiting hypometabolism in right temporal gyrus, right insula, and left cingulate.

There is enormous literature, which supports the notion that ECT brings about changes in $\mathrm{rCBF}$ and regional metabolism. A post-ECT reduction in $\mathrm{rCBF}$ and glucose utilization in the cortex (particularly in dorsolateral and medial prefrontal cortex, superior frontal regions and temporal cortex) along with increase in flow across the amygdala, parahippocampal gyri, pons and other limbic/paralimbic structures has been reported in patients with depression. ${ }^{15,16)}$ However, several studies report contradictory findings in this regards. Yatham et al. ${ }^{17)}$ reported no significant change in blood flow. Conversely, increased $\mathrm{rCBF}$ had also been reported after an ECT course. $^{18,19)}$ Mervaala et al. ${ }^{18)}$ using SPECT showed increased metabolism in right temporal and bilateral parietal cortices.

Most of the above evidences are suggestive of definite changes in $\mathrm{rCBF}$ following ECT in patients suffering from major psychiatric disorders. These amendments in $\mathrm{rCBF}$ have association with metabolism in different brain areas which are related to therapeutic outcome.

\section{Changes in blood brain barrier}

During the ictal phase of ECT induced seizure, there occurs an up-surge in blood pressure, consequently, there may occur break in the continuity of blood brain barrier (BBB) transiently. ${ }^{20)}$ During this process, certain neuro-chemicals may get released from circulation to brain 
parenchyma which brings out specific changes (increased brain derived neurotrophic factor [BDNF] levels, angiogenesis, neurogenesis) in the microenvironment of the brain. The breach in BBB occurs only after repeated application of ECS. Accordingly, the alteration in BBB integrity may be unrelated to the brain changes following single session of electroconvulsive stimulus as evident from studies on experimental animals. ${ }^{20)}$

\section{Electroencephalography changes}

Electroencephalography (EEG) reflects the functional integrity of the cerebral cortex. EEG changes in specific brain areas during and after ECT may predict about clinical outcome as well as helps in understanding the underlying biological mechanisms of ECT. Studies correlating the therapeutic effect of ECT with EEG changes are limited. Slowing of waveform has been the commonest EEG finding, and might be associated with the clinical outcome. Some evidences suggest post-ECT delta activity in prefrontal cortex as a predictor of clinical response, irrespective of the mode of ECT. ${ }^{21,22)}$ The onset of therapeutic response depends upon the rapidity as well as the extent of slowing of EEG waves. ${ }^{23)}$ The ictal EEG changes on bilateral ECT (in comparison to unilateral ECT) is found to be more synchronous, symmetrical, uniform with high amplitude and have significant post-ictal suppression. ${ }^{24)}$ Differences exist in EEG pattern among different subtypes of depression (unipolar depression, bipolar depression and psychotic depression). These differences in the EEG characteristics fade out with application of $\mathrm{ECT}^{25)}$ A recent study by Zhao et $a{ }^{26)}{ }^{26)}$ revealed decrease in alpha activity in the fronto-temporal cortex following a series of ECT. Increase in theta $(4-7 \mathrm{~Hz})$ activity was also reported in certain brain areas. McCormick et al. ${ }^{27)}$ using low-resolution electromagnetic tomography analysis, showed sub-genual anterior cingulate cortex (SgACC) as the site of theta activity. Raised theta activity was shown to be associated with decline in psychotic symptoms in patients with psychotic depression. Additionally, the extent of decreased theta activity in the SgACC prior to treatment was positively associated with antipsychotic response of $\mathrm{ECT}^{27)}$

\section{Neurobiochemical Hypotheses}

ECT modulates the process of neurotransmission and influences the expression as well as release of a great variety of neurochemicals in brain including transcription factors, neurotransmitters, neurotrophic factors, and hormones. ${ }^{28)}$ It has an effect on transmission of almost all the major neurotransmitters in brain such as serotonin, dopamine, acetyl-choline, endogenous opioids, epinephrine and nor-epinephrine, etc. ${ }^{29,30)}$ During chemical neurotransmission, it acts at multiple levels including the neurotransmitter synthesis, neurotransmitter release, binding of neurotransmitters to their receptors as well as their reuptake. $^{30)}$

\section{Genetic changes}

Animal experiments have revealed altered expression of various target genes following acute as well as serial electroconvulsive stimulations. These genes might encode for various transcription factors, structural proteins as well as neuropeptides found in brain. For instance, Dyrvig et $a l .{ }^{31)}$ showed increased expression of genes c-Fos, Egrl, Neuritin 1, BDNF, Snap29, Synaptotagmin III, Synapsin I, Psd95 and Npy in rodent brain post-ECS. Similarly Kaneko et al. ${ }^{32)}$ demonstrated significantly increased expression of $T C F 7$ (transcription factor 7) gene using microarray analysis of mRNA derived from peripheral blood in patients with catatonic schizophrenia following repeated ECT.

The epigenetic modifications brought about by ECT have also been suggested to account for the therapeutic effects of ECT. ${ }^{33)}$ Electroconvulsive activity has been demonstrated to induce the gene Gadd45b (growth arrest and DNA-damage-inducible protein 45 beta) that has role in demethylation at the regulatory regions of genes for fibroblast growth factor 1 (FGF-1) and BDNF, factors involved in regulation of neurogenesis. ${ }^{34,35)}$ Gadd45b mediates ECT-induced dendritic proliferation in nascent neurons of hippocampal dentate gyrus. ${ }^{35,36)}$

Electroconvulsive seizure improves neuronal connectivity at the hippocampus. Single electroconvulsive stimulus produces increased expression of specific proteins like-striatal enriched protein tyrosine phosphatase $\left(\mathrm{STEP}_{61}\right)$, which dephosphorylates tyrosine from the $\mathrm{N}$-methyl-D-aspartate (NMDA) receptor and extracellular signal regulated kinase $1 / 2$ (ERK $1 / 2$ ) resulting in internalization of the receptors. ${ }^{37)}$ This physiological change has been observed in the hippocampus of rats.

Electroconvulsive seizures induce transcriptional regulation of various histone proteins, DNA modifying enzymes (DNA methyltransferase and DNA demethylase) and methyl-cytosine-phosphate-guanine-binding proteins within the hippocampus as seen in experimental animals (rats) ${ }^{38)}$ ECT produces remodelling of the chromatins by various mechanisms. The therapeutic effects may be mediated through down-regulation of c-fos and up-regu- 
lation of BDNF. ${ }^{39)}$ Another epigenetic mechanism explains the involvement of histone deacetylase enzyme that leads to post-transcriptional changes leading to down-regulation of NMDA receptor signaling pathways leading to effects of ECT. ${ }^{40)}$

However the evidences explaining possible role of ECT in modifying the epigenetic mechanisms to bring out the therapeutic effect is limited to experimental animals.

\section{Neurotrophic factors}

There is increasing evidence for role of neurotrophic factors in growth and development of brain structures as well as in pathophysiology and treatment of psychiatric disorders. ECT has been shown to change the levels of various biochemical mediators including these neurotrophic factors to effect neuroplastic changes in the brain. This trophic activity involves both neuroprotection as well as increased neuronal proliferation. Even single electroconvulsive stimulus produces proliferation of neurons at the dentate gyrus of hippocampus and newly formed neurons may survive for months. ${ }^{41,42)}$ It has been hypothesized that ECS prevents cell death through activation of survival signal pathways, and inhibition of pro-apoptotic signaling. Animal studies have shown, repeated ECS to increase proliferative signals such as the Cdk2-pRB-E2F1 cell cycle pathway and ERK pathway in brain cortex. ${ }^{43,44)}$ In addition, ECS decreases $b c l$-XS gene mediated neuronal apoptosis. ${ }^{45)}$ Moreover, ECS produces down regulation of c-Myc, an intracellular protein involved in neuronal apoptosis. c-Myc, promotes apoptosis in response to various stimuli (in association of $\mathrm{Bcl}-2$ group of proteins) and has a regulatory role on cellular proliferation and differentiation. ${ }^{44,46)}$ In the frontal cortex of rat, Jeon et $a l^{44)}$ demonstrated ubiquitin-proteasomal degradation of c-Myc after repeated ECS. Bad, a pro-apoptotic factor responsible for apoptosis also got inactivated by ECS. This trophic effect of ECS blocking apoptosis may be responsible for the therapeutic effect. ${ }^{44)}$

Among neurotropic factors BDNF has been widely studied for its putative role in mediating the effects of ECT. BDNF is a nerve growth factor classified under neurotrophin class, mediates neuronal growth, proliferation, repair and survival. ${ }^{47,48)}$ In rats, Nibuya et al. ${ }^{49)}$ demonstrated ECS to enhance the expression of hippocampal BDNF mRNA. Further pre-clinical studies on rodents support the finding of ECS altering the levels of BDNF, proteins and the tyrosine kinase receptor $\mathrm{B}$ (TrkB) mRNA in different brain areas. ${ }^{50)}$ Recent meta-analyses validate low serum BDNF (sBDNF) concentrations in depressed patients which get normalized by ECT and antidepressant treatment. A dose-response effect of ECS on BDNF has also been hypothesized. ${ }^{47,51,52)}$ These studies however disproved consistent association between sBDNF concentrations and the symptom severity or clinical response in depression. ${ }^{47,51)}$ In contrast several researches suggest post-ECT improvements in illness not to be associated with increase in sBDNF levels. ${ }^{53,54)}$ Differential BDNF expression in different areas of brain is believed to be responsible for antidepressant action of electroconvulsive seizures. ${ }^{55)}$ In rats, Taliaz et $a l .{ }^{56)}$ demonstrated the antidepressant-like effect of ECT. The effect was more dependent on ECT induced significant reduction of ventral tegmental area (VTA) BDNF expression rather than elevated hippocampal BDNF expression. Earlier researches also pointed to this contrasting BDNF action in the hippocampus and the VTA ${ }^{56)}$ It has also been hypothesized that BDNF expression differs according to duration post-ECT and further research to establish this correlation has been advised. $^{57)}$

Studies also show post-ECS increased expression of vascular endothelial growth factor (VEGF), glial cell-line derived neurotrophic factor (GDNF) and basic FGF-2. ${ }^{58-60)}$ There is growing support regarding their involvement in causation of psychiatric illnesses. ${ }^{61-64)}$

VEGF has a role in endothelial proliferation, angiogenesis, vaso-permeability, and has neurotrophic actions. ${ }^{60)}$ In animal models there had been robust VEGF induction in hippocampus post ECS. VEGF was shown to be essential and sufficient to induce the proliferation of quiescent neural progenitor cell. Genetic variation of VEGF influences human hippocampal morphology suggest that effects of VEGF as reported in rodent models extend to humans. ${ }^{65)}$ Similarly, it was reported to be significantly increased in depressed patients after ECT. ${ }^{66)}$ It has also been hypothesized that VEGF may be involved in increasing antidepressant drug concentration in brain by down-regulating P-glycoprotein (a drug efflux transporter) at the brain-blood barrier. ${ }^{60)}$

GDNF is a neurotrophic agent from transforming growth factor $\beta$ (TGF $\beta$ ) family of neurotrophins. It has a role in survival of dopaminergic neurons. ${ }^{67)}$ Low serum GDNF has been reported in major depressive disorder (MDD) patients, levels of which improved following ECT. Zhang et $a l .{ }^{68)}$ reported significantly increased serum GDNF levels in MDD patients showing response to ECT. Accordingly, GDNF was hypothesized to have a role in mediating effects of ECT.

Studies have demonstrated down-regulation of expres- 
sions of FGF-2 transcripts in MDD, more so in untreated patients. Researchers also proposed FGF-2 to have an endogenous antidepressant and anxiolytic property and its increased expression to promote response to antidepressant therapies. ${ }^{69)}$ Definite evidences for their role in mediating the effect of ECT are lacking, and it has been speculated that increase in the expression might just be an unrelated compensatory response.

Several other biochemical mediators have been proposed to play a role in ECT functioning. A recent study supports the possible involvement of tissue plasminogen activator (TPA) for the therapeutic effect of ECT. ${ }^{2)}$ Electrical stimulation of brain enhances the expression of glutamate decarboxylase-65 isoform in the GABAergic neurons releasing TPA, which results in amplification of neurogenesis in limbic system, modulation of synaptic plasticity and neurotransmission. ${ }^{2)}$

ECT changes blood levels of various other molecules associated with mood disorders such as CD40L, interleukin (IL)-8, IL-13, EGF, insulin like growth factor (IGF)-1, pancreatic polypeptide, stem cell factor, sortilin-1 etc. The changes in blood levels were more prominent after acute ECT treatment. However, robust evidence regarding their role in mediating ECT action is lacking. ${ }^{57)}$

\section{Immune system}

Ongoing researches hinted towards a possible involvement of immune system in mediating the effects of ECT. ${ }^{29)}$ A higher level of inflammatory mediators and activated immune cells in blood and cerebrospinal fluid (CSF) has been reported in patients with depression. ${ }^{70)}$ Polymorphisms in genes related to immune system may predispose individuals to develop major depression. Inflammatory mediators implicated include C-reactive protein, IL-6, IL-1, and tumor necrosis factor $\alpha$, etc. Similar pro-inflammatory states have been described in other psychiatric illnesses such as schizophrenia. Dysregulation of these immune mediators have been suggested to alter neurotransmitter synthesis and their blood levels through alterations in tryptophan-kynurenine pathway. ${ }^{71)}$ Moreover, Guloksuz et al. ${ }^{72)}$ have shown ECT to favour metabolites with neuro-protective properties. ECT temporarily increases expression of certain inflammatory cytokine genes. However, multiple sessions of ECT leads to a decline in the levels of inflammatory mediators.
Hormones

Hypothalamic-pituitary-adrenal (HPA) axis

ECT has been hypothesized to enhance release of hormones from hypothalamus into CSF and blood through excitation of diencephalic structures. ${ }^{73)}$ There is a transient and selective increase in secretion of adrenocorticotrophic hormone, cortisol and prolactin that returns to baseline in few hours following ECT. Evidences indicate disturbed levels of stress hormones in patients with mood disorder. In patients with depression, studies have consistently reported HPA axis hyper-function. This is evident in form of elevated cortisol levels and decreased cortisol suppression on dexamethasone suppression test. High cortisol levels have negative impact on neurogenesis, gliogenesis and are related to atrophy of structures such as hippocampus. ${ }^{74)}$ The zone nearby node of Ranvier (i.e., paranode) in neurons has been suggested to be especially vulnerable to corticosteroids and stress related injury. It is considered as a crucial site of glial-neuronal interaction and dysfunctions there might result in neuropsychiatric manifestations. ${ }^{75)}$ ECT has been shown to reduce the cortisol levels to normal among patients with MDD in due course. Whether these changes in levels of hormones have therapeutic implications or are manifestations of ECS related stress and to secondary other changes in brain is still unclear. ${ }^{73)}$ It is also not known for sure that how changes in hormone levels affect amelioration of symptoms related to psychiatric illnesses. However, ECT has been demonstrated to reduce cortisol induced inhibition of neuroplasticity. ${ }^{76,77)}$

\section{Mono-aminergic neurotransmitters}

Disturbed monoaminergic neurotransmission has been proposed since long in depressed patients. Post mortem studies have demonstrated increased $\alpha_{2}$-adrenoceptor binding due to decreased release of noradrenaline in brain of suicide victims. Results from studies on rodents suggest that the therapeutic effect of ECS may be mediated through an increased release of noradrenaline indicated by a compensatory reduction in $\alpha_{2}$-adrenoceptor binding. ${ }^{78)}$ The decreases in $\alpha_{2}$-adrenoceptor binding were more pronounced in areas of frontal cortex having robust connections with amygdala and hippocampus, the structures involved in processing of emotions and memory, respectively. In MDD patients dopamine transporter binding is reduced in the substantia nigra, striatum, thalamus, and anterior cingulate. ECT series has been shown to elevate levels of CSF homovanillic acid and 5-hydrox- 
yindoleacetic acid, the metabolites of monoamine neurotransmitters. ${ }^{79)}$ Transiently increased dopamine receptor binding has also been reported. ${ }^{80)}$ Moreover, ECT has been proposed to modulate dopaminergic receptors and enhance dopamine neurotransmission in brain.

\section{Serotonin}

Serotonergic neurotransmitter system is well known to have implications in disorders of mood and psychosis. Various antidepressants targeting this system have been developed. Serotonin transporter (5-HTTLPR) and norepinephrine transporter (NET182C) polymorphisms have been suggested to be associated with ECT treatment response. ${ }^{81)}$ However, studies conducted on rodents in past using radio-ligands or measuring serotonin (5-hydroxytryptamine; 5-HT) release have provided ambiguous results regarding effect of ECS on receptor sensitivity. ${ }^{82)}$ Findings of human studies measuring post ECT blunting of cortisol response over $5-\mathrm{HT}_{1 \mathrm{~A}}$ receptor agonist treatment were also contradicting. Researchers reported both increased response as well as no change in $5-\mathrm{HT}_{1 \mathrm{~A}}$ receptor sensitivity. Antidepressant medications are associated with initial decline in $5-\mathrm{HT}_{1 \mathrm{~A}}$ receptor down-regulation, before resetting of serotonergic system occurs in neurons. Likewise, a recent PET study on MDD patients showed a post ECT decrease in $5-\mathrm{HT}_{1 \mathrm{~A}}$ receptor binding in various brain areas such as orbito-frontal cortex, ACC, hippocampus and amygdala. ${ }^{83)}$ However, Saijo et al. ${ }^{82)}$ using [carbonyl-11C]-WAY100635 a 5-HT $1 \mathrm{~A}$ antagonist with high affinity, reported unchanged $5-\mathrm{HT}_{1 \mathrm{~A}}$ receptor binding in depressed patients receiving ECT. Moreover, a study using neuroendocrine challenge test in patients undergoing ECT, could not find association between illness improvement and serotonergic function. ${ }^{84)}$ Similar to antidepressants, ECT also down-regulates $5-\mathrm{HT}_{2}$ receptors globally, in the brain of patients with MDD. ${ }^{85)}$ Reduction in $5-\mathrm{HT}_{2}$ receptor density is suggested to have antidepressant action. Robust evidences for the direct involvement of serotonergic system in ECT are lacking at this point of time. Further research in this domain might throw light on implications of serotonergic system in ECT action.

\section{Neuropeptide $Y$}

Neuropeptide Y (NPY) has roles in emotional regulation, processing of memory, maintaining circadian rhythms, and regulation of appetite. Moreover, it also has anticonvulsant action and gets released in response to seizure stimulation. This effect is achieved through inhibitory effect of NPY on glutamatergic neurons. Diminished NPY levels have been reported in various psychiatric disorders such as depression with suicidality, bipolar disorder and schizophrenia. ${ }^{86)}$ Repetitive spontaneous seizures have been shown to be associated with increased expression of NPY mRNA and peptide release throughout the mossy fiber pathway in cortex as well as hippocampus, not found otherwise. ${ }^{87)}$ ECT has been shown to be associated with elevated NPY levels in CSF of patients with depression. ${ }^{79)}$ Present evidences suggest that NPY may be involved with mechanism of action of ECT.

\section{Glutamate}

Glutamate is the most abundant excitatory neurotransmitter in human brain. Excessive release of glutamate is associated with overstimulation of extrasynaptic NMDA receptors leading to calcium influx inside neurons subsequently causing excitotoxic neuronal damage. The cystine glutamate antiporter located on astrocytes is involved in cystine uptake into cell in return for glutamate release. Cystine gets reduced to cysteine, a substrate for the synthesis of glutathione which has antioxidant properties. Extracellular glutamate excess competitively prevents cystine uptake inside cell, triggering oxidative stress related cellular death. ${ }^{88)}$ Increased glutamate/GABA ratio was observed in prefrontal cortex and hippocampus in rodent model of depression (learned helplessness). ${ }^{89)}$ Elevated glutamate levels in frontal cortex were also reported through post-mortem studies. ${ }^{90)}$ Contrarily, other researchers have demonstrated reduced glutamate levels in dorso-lateral prefrontal cortex (DLPFC), amygdala, ventromedial prefrontal cortex (VMPFC) as well as in ACC in patients with depression. ${ }^{91,92)}$ However, a recent study in depressed patients elucidated distinct glutamate levels in different areas of brain. ${ }^{93,94)}$ Bernard et al. ${ }^{95)}$ demonstrated significantly altered expression of glutamate receptor and transporter gene on post-mortem analysis of locus ceruleus in levels in MDD patients. In MDD patients, altered expression of glutamate receptors genes in hippocampus has also been reported. ${ }^{96)}$ Furthermore, impaired AMPA receptor mediated glutamatergic neurotransmission has been shown in patients with schizophrenia. ${ }^{97)}$ Thus, altered glutamatergic transmission has been implicated to have role in psychiatric disorders.

Dong et al.$^{98)}$ in experiment on rats showed ECT to lower down the levels of increased glutamate significantly in hippocampus of depressed animals. Moreover, stimulation threshold of NMDA receptors was reduced and the expression of NMDA receptor was up-regulated in the rat 
brain following ECT. ${ }^{98)}$ Similarly, ECT has been reported to rectify glutamatergic alterations in specific areas of brain (i.e., DLPFC) in patients with depression. ${ }^{92,99)}$ In addition, ECT increases glutamate levels in subgenual ACC and lowers the levels in left hippocampus in patients with depression. This glutamate normalizing action of ECT relates with improvement in disorders of mood. ${ }^{93)}$

\section{Neuroplastic Changes}

In psychiatric disorders alterations in volume of brain structures has been consistently reported. Studies have also demonstrated ECT to trigger changes in volume of whole brain as well as its components such as gray matter, white matter and other brain structures. ${ }^{100,101)}$ These changes are more pronounced in areas with greater connection to prefrontal cortex and other limbic structures involved in regulation of mood. ${ }^{102-104)}$ ECT brings about neuroplastic changes at synapse (synaptogenesis), neurons (neurogenesis), dendrites (dendrogenesis), vasculature (angiogenesis), as well as glial cells and their processes (gliogenesis). Neuroplastic changes have been noticed as early as after a single electroconvulsive stimulus. In rodents, ECS enhances markers of glial activation within hours of its application. ${ }^{105)}$ In experimental animals, repeated ECS instigates long lasting, mossy fiber sprouting in limbic structures of brain. This change was not associated with neuronal loss, ruling out it being just a compensatory activity. ${ }^{106)} \mathrm{ECT}$ in rodents (rats) may produce $30 \%$ increase in the population of endothelial cell by means of endothelial cell proliferation. ${ }^{107)}$ The increase in angiogenesis may be related to the metabolic activity of specific brain regions.

A great deal of research has been performed pertaining to the neuroplastic effect of ECT in patients with MDD. Moreover, significant modulations in volume of brain substructures such as hippocampus, amygdala, anterior cingulate gyrus and medial and inferior temporal cortex have been reported with ECT. ${ }^{101,108-110)}$ However, the evidences regarding nature and extent of alterations as well as their correlation with response are contradicting.

In patients with MDD, MRI studies have reported increase in hippocampal volume (normalization) after a course of ECT. ${ }^{101,102)}$ The ECT induced incremental changes in volume of hippocampus as well as amygdala can be observed within 72 hours of treatment initiation. Furthermore, smaller baseline hippocampus volume had been suggested to be associated with greater post ECT clinical response. ${ }^{103)}$ However, several other studies do not support this finding. ${ }^{111,112)}$ Abbott et al. ${ }^{102)}$ showed
ECT response and symptom improvement to be associated with increase in hippocampal functional connectivity (FC) rather than change in hippocampal volume. Additionally, FC changes were not found to correlate with hippocampal volume changes.

Several researches have also reported significant volume change in amygdala with ECT. ${ }^{103)}$ Moreover, pretreatment volume as well as extent of enlargement had been suggested to relate with improvement of clinical symptoms of depression. Ota et al. ${ }^{101)}$ reported change in right amygdala volume to relate with improvement of clinical symptoms of depression. Instead, Ten Doesschate et al. ${ }^{111)}$ held left amygdala volume to have a greater predictive value. However, evidences regarding these associations are conflicting and require further exploration.

Neuroimaging studies have also revealed, ECT to modify the FC of brain areas. Mounting evidences suggest alterations in connectivity within functional networks as well as between distinct networks, among patients with depression. These networks are associated with top down regulation of attention and mood (fronto-parietal network), processing of emotion (the affective network and the ventral attention network) as well as internally or externally oriented attention (default mode [DM] network and dorsal attention network). ${ }^{113)}$ In depression communication is impaired in both task-negative and task-positive networks. Studies have shown hyperconnectivity pattern in DM network in depression. ${ }^{113,114)}$ Connolly et al. ${ }^{115)}$ studied resting state FC of SgACC in patients with MDD and revealed increased FC of SgACC with amygdala as well as insula. Moreover, connectivity was decreased between the SgACC and left precuneus; thus, highlighting impairment in above mentioned networks. ${ }^{115)}$ Reduction of FC within fronto-parietal network also occurs in patients with MDD. ${ }^{113)}$ Likewise, altered FC in DM network, salience network (the affective network and the ventral attention network) and dorsal attention network has been demonstrated in patients with schizophrenia. ${ }^{116,117)}$

ECT normalizes resting state FC of brain networks. ${ }^{102,118)}$ It has been shown to normalize decreased hippocampal connectivity in patients with MDD. Furthermore, the elevation of connectivity was reported to correlate with symptom improvement in depression. ${ }^{102)}$ The decline in resting-state FC has been observed as early as after single ECT session. ${ }^{104)}$ ECT was also shown to normalize (by increasing) network connectivity between posterior DM and dorso-medial prefrontal cortex (DMPFC) as well as between posterior DM and left DLPFC. ${ }^{119)}$ Connectivity in parahippocampal gyri as well as VMPFC, the com- 
ponents of DM, subsides to normalize with ECT. ${ }^{120)}$ The DM network have implications in depressive ruminations and impaired top-down regulation; thus, normalizing changes in FC may help in ameliorating symptoms of depression. ${ }^{119,121)}$ Cano et al. ${ }^{104)}$ reported decreased FC between intra-limbic structures (amygdala and SgACC) and increased FC between limbic-prefrontal networks (right amygdala and right DLPFC) after ECT. They suggested that FC changes occur initially in intra-limbic networks and subsequently extend to limbic-prefrontal networks. Changes in resting state $\mathrm{FC}$ in several brain structures (such as ACC, thalamus and hippocampus) are associated both with ECT application as well as clinical improvement. ${ }^{118)}$ Accordingly, of the various FC changes that occur with ECT all might not be specific to a diagnosis or relate with clinical improvement. ${ }^{122}$

\section{CONCLUSION}

Decades of research performed to elucidate the mechanism of ECT outlined a vast field of study that may involve numerous intricate biologic processes, including alterations in neuroplasticity, levels of various neurotrophic factors and neurotransmitters, FC, immune mechanisms, neuroendocrine function as well as epigenetic processes. Despite the evidences explaining neurobiological mechanisms of ECT, inconsistent research findings preclude from drawing firm inferences. This attributable to lacunae in present literature, such as lack of homogeneity in research methodology and study population, small to moderate sample size and lack of control group in numerous studies. Moreover, the cause-effect relationship between findings and therapeutic effects of ECT could not be established with absolute certainty and even it is also not very prudent to assume about a single mechanism that can explain the therapeutic effect of ECT.

The future researches focusing on neurobiologic mechanisms of ECT need to address following areas of concern; use of control groups, homogenous study methodology in a larger study population and to attend the grey areas where contrasting evidences exist.

\section{REFERENCES}

1. Sundsted KK, Burton MC, Shah R, Lapid MI. Preanesthesia medical evaluation for electroconvulsive therapy: a review of the literature. J ECT 2014:30:35-42.

2. Hoirisch-Clapauch S, Mezzasalma MA, Nardi AE. Pivotal role of tissue plasminogen activator in the mechanism of action of electroconvulsive therapy. $J$ Psychopharmacol 2014; 28:99-105

3. Medda P, Toni C, Perugi G. The mood-stabilizing effects of electroconvulsive therapy. J ECT 2014;30:275-282.

4. Sadock BJ, Sadock VA, Ruiz P. Kaplan and Sadock's comprehensive textbook of psychiatry. 9th ed. Philadelphia, PA:Lippincott Williams \& Wilkins;2009.

5. Swartz CM. A mechanism of seizure induction by electricity and its clinical implications. J ECT 2014;30:94-97.

6. Takano H, Motohashi N, Uema T, Ogawa K, Ohnishi T, Nishikawa M, et al. Differences in cerebral blood flow between missed and generalized seizures with electroconvulsive therapy: a positron emission tomographic study. Epilepsy Res 2011;97:225-228.

7. Deng ZD, Lisanby SH, Peterchev AV. Controlling stimulation strength and focality in electroconvulsive therapy via current amplitude and electrode size and spacing: comparison with magnetic seizure therapy. J ECT 2013;29: 325-335.

8. Enev M, McNally KA, Varghese G, Zubal IG, Ostroff RB, Blumenfeld $\mathrm{H}$. Imaging onset and propagation of ECTinduced seizures. Epilepsia 2007;48:238-244.

9. Kranaster L, Plum P, Hoyer C, Sartorius A, Ullrich H. Burst suppression: a more valid marker of postictal central inhibition? J ECT 2013;29:25-28.

10. Takano H, Motohashi N, Uema T, Ogawa K, Ohnishi T, Nishikawa $\mathrm{M}$, et al. Changes in regional cerebral blood flow during acute electroconvulsive therapy in patients with depression: positron emission tomographic study. $\mathrm{Br}$ J Psychiatry 2007;190:63-68.

11. Allen P, Chaddock CA, Egerton A, Howes OD, Bonoldi I, Zelaya F, et al. Resting hyperperfusion of the hippocampus, midbrain, and basal ganglia in people at high risk for psychosis. Am J Psychiatry 2016;173:392-399.

12. Hua J, Brandt AS, Lee S, Blair NI, Wu Y, Lui S, et al. Abnormal grey matter arteriolar cerebral blood volume in schizophrenia measured with $3 D$ inflow-based vascularspace-occupancy MRI at 7T. Schizophr Bull 2017;43: 620-632.

13. Berggren Å, Gustafson L, Höglund P, Johanson A. A long-term follow-up of clinical response and regional cerebral blood flow changes in depressed patients treated with ECT. J Affect Disord 2014;167:235-243.

14. Hosokawa T, Momose T, Kasai K. Brain glucose metabolism difference between bipolar and unipolar mood disorders in depressed and euthymic states. Prog Neuropsychopharmacol Biol Psychiatry 2009;33:243-250.

15. Suwa T, Namiki C, Takaya S, Oshita A, Ishizu K, Fukuyama $\mathrm{H}$, et al. Corticolimbic balance shift of regional glucose metabolism in depressed patients treated with ECT. J Affect Disord 2012;136:1039-1046.

16. Nobler MS, Oquendo MA, Kegeles LS, Malone KM, Campbell CC, Sackeim HA, et al. Decreased regional brain metabolism after ect. Am J Psychiatry 2001;158: 305-308.

17. Yatham LN, Clark CC, Zis AP. A preliminary study of the effects of electroconvulsive therapy on regional brain glucose metabolism in patients with major depression. $J$ ECT 2000;16:171-176.

18. Mervaala E, Könönen M, Föhr J, Husso-Saastamoinen M, Valkonen-Korhonen M, Kuikka JT, et al. SPECT and neuropsychological performance in severe depression treated with ECT. J Affect Disord 2001;66:47-58.

19. Bonne O, Krausz Y, Shapira B, Bocher M, Karger H, Gorfine $\mathrm{M}$, et al. Increased cerebral blood flow in depressed patients responding to electroconvulsive therapy. J Nucl Med 1996;37:1075-1080.

20. Andrade C, Bolwig TG. Electroconvulsive therapy, hyper- 
tensive surge, blood-brain barrier breach, and amnesia: exploring the evidence for a connection. J ECT 2014;30: 160-164.

21. Sackeim HA, Luber B, Katzman GP, Moeller JR, Prudic $\mathrm{J}$, Devanand DP, et al. The effects of electroconvulsive therapy on quantitative electroencephalograms. Relationship to clinical outcome. Arch Gen Psychiatry 1996;53:814824.

22. Fink M. EEG changes with antipsychotic drugs. Am J Psychiatry 2002;159:1439; discussion 1439.

23. Folkerts H. The ictal electroencephalogram as a marker for the efficacy of electroconvulsive therapy. Eur Arch Psychiatry Clin Neurosci 1996;246:155-164.

24. Krystal AD, Weiner RD, McCall WV, Shelp FE, Arias R, Smith P. The effects of ECT stimulus dose and electrode placement on the ictal electroencephalogram: an intraindividual crossover study. Biol Psychiatry 1993;34:759-767.

25. Wahlund B, Piazza P, von Rosen D, Liberg B, Liljenström H. Seizure (Ictal)--EEG characteristics in subgroups of depressive disorder in patients receiving electroconvulsive therapy (ECT)--a preliminary study and multivariate approach. Comput Intell Neurosci 2009;2009:965209.

26. Zhao L, Jiang Y, Zhang H. Effects of modified electroconvulsive therapy on the electroencephalogram of schizophrenia patients. Springerplus 2016;5:1063.

27. McCormick LM, Yamada T, Yeh M, Brumm MC, Thatcher RW. Antipsychotic effect of electroconvulsive therapy is related to normalization of subgenual cingulate theta activity in psychotic depression. J Psychiatr Res 2009;43:553560 .

28. Segi-Nishida E. Exploration of new molecular mechanisms for antidepressant actions of electroconvulsive seizure. Biol Pharm Bull 2011;34:939-944.

29. Rosenquist PB, Miller B, Pillai A. The antipsychotic effects of ECT: a review of possible mechanisms. J ECT 2014;30: 125-131.

30. Baldinger P, Lotan A, Frey R, Kasper S, Lerer B, Lanzenberger R. Neurotransmitters and electroconvulsive therapy. J ECT 2014;30:116-121.

31. Dyrvig M, Christiansen SH, Woldbye DP, Lichota J. Temporal gene expression profile after acute electroconvulsive stimulation in the rat. Gene 2014;539:8-14.

32. Kaneko T, Kanazawa T, Nishiguchi M, Kikuyama H, Tsutsumi A, Uenishi $\mathrm{H}$, et al. Microarray analysis of human blood during electroconvulsive therapy. J ECT 2015;31:234-237.

33. de Jong JO, Arts B, Boks MP, Sienaert P, van den Hove DL, Kenis G, et al. Epigenetic effects of electroconvulsive seizures. J ECT 2014;30:152-159.

34. Barreto G, Schäfer A, Marhold J, Stach D, Swaminathan SK, Handa V, et al. Gadd45a promotes epigenetic gene activation by repair-mediated DNA demethylation. Nature 2007;445:671-675.

35. Ma DK, Jang MH, Guo JU, Kitabatake Y, Chang ML, Pow-Anpongkul N, et al. Neuronal activity-induced Gadd45b promotes epigenetic DNA demethylation and adult neurogenesis. Science 2009;323:1074-1077.

36. Jun H, Hussaini SM, Cho CH, Welby J, Jang $\mathrm{MH}$. Gadd45b mediates electroconvulsive shock induced proliferation of hippocampal neural stem cells. Brain Stimul 2015;8:1021-1024.

37. Jang SS, Royston SE, Lee G, Wang S, Chung HJ. Seizureinduced regulations of amyloid- $\beta$, step61, and step61 substrates involved in hippocampal synaptic plasticity. Neural Plast 2016;2016:2123748.
38. Pusalkar M, Ghosh S, Jaggar M, Husain BF, Galande S, Vaidya VA. Acute and chronic electroconvulsive seizures (ecs) differentially regulate the expression of epigenetic machinery in the adult rat hippocampus. Int $J$ Neuropsychopharmacol 2016;19:pyw040.

39. Tsankova NM, Kumar A, Nestler EJ. Histone modifications at gene promoter regions in rat hippocampus after acute and chronic electroconvulsive seizures. J Neurosci 2004; 24:5603-5610.

40. Park HG, Yu HS, Park S, Ahn YM, Kim YS, Kim SH. Repeated treatment with electroconvulsive seizures induces $H D A C 2$ expression and down-regulation of NMDA receptor- related genes through histone deacetylation in the rat frontal cortex. Int $J$ Neuropsychopharmacol 2014;17: 1487-1500.

41. Madsen TM, Treschow A, Bengzon J, Bolwig TG, Lindvall $\mathrm{O}$, Tingström A. Increased neurogenesis in a model of electroconvulsive therapy. Biol Psychiatry 2000;47:10431049.

42. Ito M, Seki T, Liu J, Nakamura K, Namba T, Matsubara $\mathrm{Y}$, et al. Effects of repeated electroconvulsive seizure on cell proliferation in the rat hippocampus. Synapse 2010; 64:814-821.

43. Kim Y, Seo MS, Kang UG, Yoon SC, Ahn YM, Kim YS, et al. Activation of Cdk2-pRB-E2F1 cell cycle pathway by repeated electroconvulsive shock in the rat frontal cortex. Biol Psychiatry 2005;57:107-109.

44. Jeon WJ, Kim SH, Seo MS, Kim Y, Kang UG, Juhnn YS, et al. Repeated electroconvulsive seizure induces c-Myc down-regulation and Bad inactivation in the rat frontal cortex. Exp Mol Med 2008;40:435-444.

45. Kondratyev A, Sahibzada N, Gale K. Electroconvulsive shock exposure prevents neuronal apoptosis after kainic acid-evoked status epilepticus. Brain Res Mol Brain Res 2001;91:1-13.

46. Nilsson JA, Cleveland JL. Myc pathways provoking cell suicide and cancer. Oncogene 2003;22:9007-9021.

47. Brunoni AR, Baeken C, Machado-Vieira R, Gattaz WF, Vanderhasselt MA. BDNF blood levels after electroconvulsive therapy in patients with mood disorders: a systematic review and meta-analysis. World J Biol Psychiatry 2014; 15:411-418.

48. $\mathrm{Hu}$ Y, Yu X, Yang F, Si T, Wang W, Tan Y, et al. The level of serum brain-derived neurotrophic factor is associated with the therapeutic efficacy of modified electroconvulsive therapy in Chinese patients with depression. $J$ ECT 2010;26:121-125.

49. Nibuya M, Sugiyama H, Shioda K, Nakamura K, Nishijima K. ECT for the treatment of psychiatric symptoms in Basedow's disease. J ECT 2002;18:54-57.

50. Altar CA, Whitehead RE, Chen R, Wörtwein G, Madsen TM. Effects of electroconvulsive seizures and antidepressant drugs on brain-derived neurotrophic factor protein in rat brain. Biol Psychiatry 2003;54:703-709.

51. Molendijk ML, Spinhoven P, Polak M, Bus BA, Penninx BW, Elzinga BM. Serum BDNF concentrations as peripheral manifestations of depression: evidence from a systematic review and meta-analyses on 179 associations (N=9484). Mol Psychiatry 2014;19:791-800.

52. Polyakova M, Schroeter ML, Elzinga BM, Holiga S, Schoenknecht P, de Kloet ER, et al. Brain-derived neurotrophic factor and antidepressive effect of electroconvulsive therapy: systematic review and meta-analyses of the preclinical and clinical literature. PLoS One 2015;10: e0141564. 
53. Rapinesi C, Kotzalidis GD, Curto M, Serata D, Ferri VR, Scatena $\mathrm{P}$, et al. Electroconvulsive therapy improves clinical manifestations of treatment-resistant depression without changing serum BDNF levels. Psychiatry Res 2015;227:171-178.

54. Gedge L, Beaudoin A, Lazowski L, du Toit R, Jokic R, Milev R. Effects of electroconvulsive therapy and repetitive transcranial magnetic stimulation on serum brain-derived neurotrophic factor levels in patients with depression. Front Psychiatry 2012;3:12.

55. Marano CM, Phatak P, Vemulapalli UR, Sasan A, Nalbandyan MR, Ramanujam S, et al. Increased plasma concentration of brain-derived neurotrophic factor with electroconvulsive therapy: a pilot study in patients with major depression. J Clin Psychiatry 2007;68:512-517.

56. Taliaz D, Nagaraj V, Haramati S, Chen A, Zangen A. Altered brain-derived neurotrophic factor expression in the ventral tegmental area, but not in the hippocampus, is essential for antidepressant-like effects of electroconvulsive therapy. Biol Psychiatry 2013;74:305-312.

57. Stelzhammer V, Guest PC, Rothermundt M, Sondermann C, Michael N, Schwarz E, et al. Electroconvulsive therapy exerts mainly acute molecular changes in serum of major depressive disorder patients. Eur Neuropsychopharmacol 2013;23:1199-1207.

58. Kondratyev A, Ved R, Gale K. The effects of repeated minimal electroconvulsive shock exposure on levels of mRNA encoding fibroblast growth factor-2 and nerve growth factor in limbic regions. Neuroscience 2002;114: 411-416.

59. Newton SS, Collier EF, Hunsberger J, Adams D, Terwilliger $\mathrm{R}$, Selvanayagam E, et al. Gene profile of electroconvulsive seizures: induction of neurotrophic and angiogenic factors. $J$ Neurosci 2003;23:10841-10851.

60. Minelli A, Maffioletti E, Bortolomasi M, Conca A, Zanardini R, Rillosi L, et al. Association between baseline serum vascular endothelial growth factor levels and response to electroconvulsive therapy. Acta Psychiatr Scand 2014;129:461-466.

61. Schmidt HD, Shelton RC, Duman RS. Functional biomarkers of depression: diagnosis, treatment, and pathophysiology. Neuropsychopharmacology 2011;36:2375-2394.

62. Liu X, Zhang T, He S, Hong B, Chen Z, Peng D, et al. Elevated serum levels of FGF-2, NGF and IGF-1 in patients with manic episode of bipolar disorder. Psychiatry Res 2014;218:54-60.

63. Clark-Raymond A, Halaris A. VEGF and depression: a comprehensive assessment of clinical data. $J$ Psychiatr Res 2013;47:1080-1087.

64. Lin PY, Tseng PT. Decreased glial cell line-derived neurotrophic factor levels in patients with depression: a metaanalytic study. J Psychiatr Res 2015;63:20-27.

65. Blumberg HP, Wang F, Chepenik LG, Kalmar JH, Edmiston E, Duman RS, et al. Influence of vascular endothelial growth factor variation on human hippocampus morphology. Biol Psychiatry 2008;64:901-903.

66. Minelli A, Zanardini R, Abate M, Bortolomasi M, Gennarelli M, Bocchio-Chiavetto L. Vascular Endothelial Growth Factor (VEGF) serum concentration during electroconvulsive therapy (ECT) in treatment resistant depressed patients. Prog Neuropsychopharmacol Biol Psychiatry 2011;35:1322-1325.

67. Jaumotte JD, Zigmond MJ. Comparison of GDF5 and GDNF as neuroprotective factors for postnatal dopamine neurons in ventral mesencephalic cultures. $J$ Neurosci Res
2014;92:1425-1433.

68. Zhang X, Zhang Z, Sha W, Xie C, Xi G, Zhou H, et al. Electroconvulsive therapy increases glial cell-line derived neurotrophic factor (GDNF) serum levels in patients with drug-resistant depression. Psychiatry Res 2009;170:273275.

69. Turner CA, Watson SJ, Akil H. Fibroblast growth factor-2: an endogenous antidepressant and anxiolytic molecule? Biol Psychiatry 2012;72:254-255.

70. Bufalino C, Hepgul N, Aguglia E, Pariante CM. The role of immune genes in the association between depression and inflammation: a review of recent clinical studies. Brain Behav Immun 2013;31:31-47.

71. Connor TJ, Starr N, O'Sullivan JB, Harkin A. Induction of indolamine 2,3-dioxygenase and kynurenine 3-monooxygenase in rat brain following a systemic inflammatory challenge: a role for IFN-gamma? Neurosci Lett 2008;441:29-34.

72. Guloksuz S, Arts B, Walter S, Drukker M, Rodriguez L, Myint AM, et al. The impact of electroconvulsive therapy on the tryptophan-kynurenine metabolic pathway. Brain Behav Immun 2015;48:48-52.

73. Haskett RF. Electroconvulsive therapy's mechanism of action: neuroendocrine hypotheses. J ECT 2014;30:107-110.

74. O'Brien JT, Lloyd A, McKeith I, Gholkar A, Ferrier N. A longitudinal study of hippocampal volume, cortisol levels, and cognition in older depressed subjects. Am J Psychiatry 2004;161:2081-2090.

75. Edgar N, Sibille E. A putative functional role for oligodendrocytes in mood regulation. Transl Psychiatry 2012;2: el109.

76. Wennström M, Hellsten J, Ekstrand J, Lindgren H, Tingström A. Corticosterone-induced inhibition of gliogenesis in rat hippocampus is counteracted by electroconvulsive seizures. Biol Psychiatry 2006;59:178-186.

77. Hellsten J, Wennström M, Mohapel P, Ekdahl CT, Bengzon J, Tingström A. Electroconvulsive seizures increase hippocampal neurogenesis after chronic corticosterone treatment. Eur J Neurosci 2002;16:283-290.

78. Lillethorup TP, Iversen P, Fontain J, Wegener G, Doudet DJ, Landau AM. Electroconvulsive shocks decrease $\alpha 2$ adrenoceptor binding in the Flinders rat model of depression. Eur Neuropsychopharmacol 2015;25:404-412.

79. Nikisch G, Mathé AA. CSF monoamine metabolites and neuropeptides in depressed patients before and after electroconvulsive therapy. Eur Psychiatry 2008;23:356-359.

80. Landau AM, Chakravarty MM, Clark CM, Zis AP, Doudet DJ. Electroconvulsive therapy alters dopamine signaling in the striatum of non-human primates. Neuropsychopharmacology 2011;36:511-518.

81. Kautto M, Kampman O, Mononen N, Lehtimäki T, Haraldsson S, Koivisto PA, et al. Serotonin transporter (5-HTTLPR) and norepinephrine transporter (NET) gene polymorphisms: susceptibility and treatment response of electroconvulsive therapy in treatment resistant depression. Neurosci Lett 2015;590:116-120.

82. Saijo T, Takano A, Suhara T, Arakawa R, Okumura M, Ichimiya $\mathrm{T}$, et al. Effect of electroconvulsive therapy on 5-HTIA receptor binding in patients with depression: a PET study with [11C]WAY 100635. Int J Neuropsychopharmacol 2010;13:785-791.

83. Lanzenberger R, Baldinger P, Hahn A, Ungersboeck J, Mitterhauser M, Winkler D, et al. Global decrease of serotonin-1A receptor binding after electroconvulsive therapy in major depression measured by PET. Mol Psychiatry 2013;18:93-100. 
84. Goto S, Terao T, Hoaki N, Wang Y, Tsuchiyama K, Araki $\mathrm{Y}$, et al. Is serotonergic function associated with the antidepressant effects of modified-electroconvulsive therapy? $J$ Affect Disord 2012;136:1062-1066.

85. Yatham LN, Liddle PF, Lam RW, Zis AP, Stoessl AJ, Sossi V, et al. Effect of electroconvulsive therapy on brain 5-HT(2) receptors in major depression. Br J Psychiatry 2010;196:474-479.

86. Ozsoy S, Olguner Eker O, Abdulrezzak U. The effects of antidepressants on neuropeptide $Y$ in patients with depression and anxiety. Pharmacopsychiatry 2016;49:26-31.

87. Altar CA, Laeng P, Jurata LW, Brockman JA, Lemire A, Bullard J, et al. Electroconvulsive seizures regulate gene expression of distinct neurotrophic signaling pathways. $J$ Neurosci 2004;24:2667-2677.

88. Liu X, Albano R, Lobner D. FGF-2 induces neuronal death through upregulation of system $x c-$. Brain Res 2014; 1547:25-33.

89. Sartorius A, Mahlstedt MM, Vollmayr B, Henn FA, Ende G. Elevated spectroscopic glutamate/gamma-amino butyric acid in rats bred for learned helplessness. Neuroreport 2007; 18:1469-1473.

90. Hashimoto K, Sawa A, Iyo M. Increased levels of glutamate in brains from patients with mood disorders. Biol Psychiatry 2007;62:1310-1316.

91. Hasler G, van der Veen JW, Tumonis T, Meyers N, Shen $\mathrm{J}$, Drevets WC. Reduced prefrontal glutamate/glutamine and gamma-aminobutyric acid levels in major depression determined using proton magnetic resonance spectroscopy. Arch Gen Psychiatry 2007;64:193-200.

92. Pfleiderer B, Michael N, Erfurth A, Ohrmann P, Hohmann $\mathrm{U}$, Wolgast $\mathrm{M}$, et al. Effective electroconvulsive therapy reverses glutamate/glutamine deficit in the left anterior cingulum of unipolar depressed patients. Psychiatry Res 2003;122:185-192.

93. Njau S, Joshi SH, Espinoza R, Leaver AM, Vasavada M, Marquina A, et al. Neurochemical correlates of rapid treatment response to electroconvulsive therapy in patients with major depression. J Psychiatry Neurosci 2016;41: 150177.

94. Grimm S, Luborzewski A, Schubert F, Merkl A, Kronenberg $\mathrm{G}$, Colla $\mathrm{M}$, et al. Region-specific glutamate changes in patients with unipolar depression. J Psychiatr Res 2012;46:1059-1065.

95. Bernard R, Kerman IA, Thompson RC, Jones EG, Bunney $\mathrm{WE}$, Barchas JD, et al. Altered expression of glutamate signaling, growth factor, and glia genes in the locus coeruleus of patients with major depression. Mol Psychiatry 2011;16:634-646.

96. Duric V, Banasr M, Stockmeier CA, Simen AA, Newton $\mathrm{SS}$, Overholser JC, et al. Altered expression of synapse and glutamate related genes in post-mortem hippocampus of depressed subjects. Int J Neuropsychopharmacol 2013;16: 69-82.

97. Beneyto M, Meador-Woodruff JH. Lamina-specific abnormalities of AMPA receptor trafficking and signaling molecule transcripts in the prefrontal cortex in schizophrenia. Synapse 2006;60:585-598.

98. Dong J, Min S, Wei K, Li P, Cao J, Li Y. Effects of electroconvulsive therapy and propofol on spatial memory and glutamatergic system in hippocampus of depressed rats. J ECT 2010;26:126-130.

99. Michael N, Erfurth A, Ohrmann P, Arolt V, Heindel W, Pfleiderer B. Metabolic changes within the left dorsolateral prefrontal cortex occurring with electroconvulsive therapy in patients with treatment resistant unipolar depression. Psychol Med 2003;33:1277-1284.

100. Lyden H, Espinoza RT, Pirnia T, Clark K, Joshi SH, Leaver AM, et al. Electroconvulsive therapy mediates neuroplasticity of white matter microstructure in major depression. Transl Psychiatry 2014;4:e380.

101. Ota M, Noda T, Sato N, Okazaki M, Ishikawa M, Hattori $\mathrm{K}$, et al. Effect of electroconvulsive therapy on gray matter volume in major depressive disorder. J Affect Disord 2015;186:186-191.

102. Abbott CC, Jones T, Lemke NT, Gallegos P, McClintock $\mathrm{SM}$, Mayer $\mathrm{AR}$, et al. Hippocampal structural and functional changes associated with electroconvulsive therapy response. Transl Psychiatry 2014;4:e483.

103. Joshi SH, Espinoza RT, Pirnia T, Shi J, Wang Y, Ayers $\mathrm{B}$, et al. Structural plasticity of the hippocampus and amygdala induced by electroconvulsive therapy in major depression. Biol Psychiatry 2016;79:282-292.

104. Cano M, Cardoner N, Urretavizcaya M, Martínez-Zalacaín I, Goldberg X, Via E, et al. Modulation of limbic and prefrontal connectivity by electroconvulsive therapy in treatment-resistant depression: a preliminary study. Brain Stimul 2016;9:65-71.

105. Jansson L, Wennström M, Johanson A, Tingström A. Glial cell activation in response to electroconvulsive seizures. Prog Neuropsychopharmacol Biol Psychiatry 2009;33: 1119-1128.

106. Vaidya VA, Siuciak JA, Du F, Duman RS. Hippocampal mossy fiber sprouting induced by chronic electroconvulsive seizures. Neuroscience 1999;89:157-166.

107. Hellsten J, West MJ, Arvidsson A, Ekstrand J, Jansson L, Wennström $\mathrm{M}$, et al. Electroconvulsive seizures induce angiogenesis in adult rat hippocampus. Biol Psychiatry 2005; $58: 871-878$.

108. Dukart J, Regen F, Kherif F, Colla M, Bajbouj M, Heuser I, et al. Electroconvulsive therapy-induced brain plasticity determines therapeutic outcome in mood disorders. Proc Natl Acad Sci U S A 2014;111:1156-1161.

109. Nordanskog P, Dahlstrand U, Larsson MR, Larsson EM, Knutsson L, Johanson A. Increase in hippocampal volume after electroconvulsive therapy in patients with depression: a volumetric magnetic resonance imaging study. J ECT 2010;26:62-67.

110. Tendolkar I, van Beek M, van Oostrom I, Mulder M, Janzing J, Voshaar RO, et al. Electroconvulsive therapy increases hippocampal and amygdala volume in therapy refractory depression: a longitudinal pilot study. Psychiatry Res 2013;214:197-203.

111. Ten Doesschate F, van Eijndhoven P, Tendolkar I, van Wingen GA, van Waarde JA. Pre-treatment amygdala volume predicts electroconvulsive therapy response. Front Psychiatry 2014;5:169.

112. Lekwauwa RE, McQuoid DR, Steffens DC. Hippocampal volume as a predictor of short-term ECT outcomes in older patients with depression. Am J Geriatr Psychiatry 2005;13: 910-913.

113. Kaiser RH, Andrews-Hanna JR, Wager TD, Pizzagalli DA. Large-scale network dysfunction in major depressive disorder: a meta-analysis of resting-state functional connectivity. JAMA Psychiatry 2015;72:603-611.

114. Gudayol-Ferré E, Peró-Cebollero M, González-Garrido AA, Guàrdia-Olmos J. Changes in brain connectivity related to the treatment of depression measured through fMRI: a systematic review. Front Hum Neurosci 2015;9:582.

115. Connolly CG, Wu J, Ho TC, Hoeft F, Wolkowitz O, 
Eisendrath S, et al. Resting-state functional connectivity of subgenual anterior cingulate cortex in depressed adolescents. Biol Psychiatry 2013;74:898-907.

116. Wang H, Zeng LL, Chen Y, Yin H, Tan Q, Hu D. Evidence of a dissociation pattern in default mode subnetwork functional connectivity in schizophrenia. Sci Rep 2015;5: 14655.

117. Kraguljac NV, White DM, Hadley JA, Visscher K, Knight $\mathrm{D}$, ver Hoef $\mathrm{L}$, et al. Abnormalities in large scale functional networks in unmedicated patients with schizophrenia and effects of risperidone. Neuroimage Clin 2015;10: 146-158.

118. Leaver AM, Espinoza R, Pirnia T, Joshi SH, Woods RP, Narr KL. Modulation of intrinsic brain activity by electroconvulsive therapy in major depression. Biol Psychiatry Cogn Neurosci Neuroimaging 2016;1:77-86.

119. Abbott CC, Lemke NT, Gopal S, Thoma RJ, Bustillo J,
Calhoun VD, et al. Electroconvulsive therapy response in major depressive disorder: a pilot functional network connectivity resting state fMRI investigation. Front Psychiatry 2013;4:10.

120. Argyelan M, Lencz T, Kaliora S, Sarpal DK, Weissman N, Kingsley PB, et al. Subgenual cingulate cortical activity predicts the efficacy of electroconvulsive therapy. Transl Psychiatry 2016;6:e789.

121. Beall EB, Malone DA, Dale RM, Muzina DJ, Koenig KA, Bhattacharrya $\mathrm{PK}$, et al. Effects of electroconvulsive therapy on brain functional activation and connectivity in depression. J ECT 2012;28:234-241.

122. Wolf RC, Nolte HM, Hirjak D, Hofer S, Seidl U, Depping MS, et al. Structural network changes in patients with major depression and schizophrenia treated with electroconvulsive therapy. Eur Neuropsychopharmacol 2016;26: 1465-1474. 